\title{
Versos sueltos, lugares comunes, poemas encontrados ${ }^{*}$
}

\author{
Loose verses, commonplaces, found poems
}

Felipe Cussen

Universidad de Santiago de Chile. Santiago, Chile

felipecussen@gmail.com

\section{RESUMEN}

En este artículo analizo tres poemas de Nicanor Parra cuya estructura está basada en la acumulación de elementos aparentemente no poéticos: "Versos sueltos", "Ideas sueltas" y "Frases". A partir de estos procedimientos, establezco relaciones con el poeta renacentista François Villon y con algunas tendencias contemporáneas como los poemas encontrados y la poesía conceptual.

Palabras clave: Nicanor Parra, poesía encontrada, poesía conceptual.

\section{ABSTRACT}

In this article I analyze three poems by Nicanor Parra, whose structure is based on the accumulation of apparently not poetic elements: "Versos sueltos", "Ideas sueltas" and "Frases". From these procedures, I establish relationships with the Renaissance poet François Villon, and some contemporary tendenciess such as found poems and conceptual poetry.

Keywords: Nicanor Parra, found poetry, conceptual poetry.

Recibido: 04.01.2013. Aceptado: 12.04.2013.

* Este artículo pertenece al proyecto Fondecyt Regular N 1131136 "Samples y loops en la poesía contemporánea”, del que soy investigador responsable. 
C6 mí no me cuentan cuentos. Esto no ha sido jamás poesía ni lo será 1 mientras el mundo no reviente y ya no nos importen ni un comino la poesía ni la prosa” (Parra, 2006: 943) ${ }^{1}$. Así se referían en 1962, de acuerdo al crítico Hernán del Solar, los detractores del reciente Versos de salón de Nicanor Parra. El cura capuchino Prudencio de Salvatierra fue aún más duro: "Me han preguntado si este librito es inmoral. Yo diría que no; es demasiado sucio para ser inmoral. Un tarro de basura no es inmoral, por muchas vueltas que le demos para examinar su contenido" (Parra, 2006: 944).

Ambos reproches ejemplifican muy bien la irritación que provocaba para muchos la creciente radicalización del proyecto antipoético. Y creo que vale la pena tomarlos en cuenta hoy, cuando existe un amplio consenso sobre el valor de la obra de Parra, y todos celebran sonrientes hasta el último de sus chistes o dibujos como la expresión de un genio universal. Es necesario recordar la profunda ruptura de paradigmas que implicó su aparición y, aún más, considero importante volver a indagar cómo sus antipoemas todavía cuestionan algunos problemas profundos de lo que entendemos convencionalmente como poesía.

Estas dos críticas recién citadas ofrecen interesantes puntos de partida para un análisis. Más allá de la perspectiva religiosa del cura Salvatierra, me llama la atención su descripción del libro como un tarro de basura. Olvidémonos por un momento de su connotación negativa, y considerémoslo como un contenedor de elementos heterogéneos, desjerarquizados e inútiles. Versos de salón contiene una secuencia muy variada de poemas, pero además, al interior de muchos de los textos, encontraremos un acopio aparentemente indiscriminado de materiales: los titulares de diversa calaña rotando en "Noticiario 1957", las enumeraciones caóticas de "Sueños" y "Mujeres", o las descoyuntadas reflexiones anotadas en "Composiciones".

"Versos sueltos" es un ejemplo más marcado de este tipo de acumulación:

\footnotetext{
${ }^{1}$ Cito la referencia de las notas de Niall Binns a las Obras completas de Parra. Al revisar directamente la reseña completa publicada en La Nación, se lee que el crítico no lo dice a título propio, sino que busca dar cuenta de las dos valoraciones contrapuestas de este libro: "Hemos observado que de este libro no se puede hablar en voz baja. Se habla a gritos, gesticulando como al comienzo de una riña que dejará un buen número de contusos. Los más serenos dicen, arqueando las cejas: 'A mí no me cuentan cuentos. Esto no ha sido jamás poesía ni lo será mientras el mundo no reviente y ya no nos importen un comino la poesía ni la prosa.' Seguridad tan grande enardece a los devotos, que empuñan las manos y anuncian atropelladamente: 'No sea infeliz, mi amigo. Aquí hay una poesía nueva. Si usted no la ve, deje su profesión de ciego y aprenda a mirar poco a poco, hasta que los ojos le respondan”" (Solar, 1962: 4).
} 
Un ojo blanco no me dice nada

Hasta cuándo posar de inteligente

Para qué completar un pensamiento.

¡Hay que lanzar al aire las ideas!

El desorden también tiene su encanto

Un murciélago lucha con el sol:

La poesía no molesta a nadie

Y la fucsia parece bailarina

(2006: 113).

Ya en esta primera estrofa encontramos una serie de opiniones o pensamientos que han sido desparramadas por el aire. Dos de sus versos, sin embargo, pueden leerse metapoéticamente: por una parte, el contenido irrelevante de sus versos pareciera confirmar que "La poesía no molesta a nadie", pero a la vez se defiende la inconexión de los elementos, pues "El desorden también tiene su encanto". Al mismo tiempo, al reunirse con otras frases irrelevantes o escuchadas al pasar (como "¿Cuánto vale ese par de pantalones?", "Pobre gente no sabe lo que dice" o "Se reparte jamón a domicilio" (113-14)), tenemos derecho a dudar de su importancia o valor prescriptivo. Aparecen, entonces, como una sugerencia escondida, a diferencia de las declaraciones más voluntaristas de un manifiesto o aquellos textos más programáticos que figuran en los primeros libros de Parra. Así, sólo de refilón podemos descubrir una poética, que pareciera corresponder con el carácter general de estos Versos de salón, es decir, una poesía que se ofrece irónicamente como inofensiva. Hacia el final del poema este punto queda particularmente destacado al oponerse de manera nada equívoca al modelo huidobriano del pequeño dios: "Yo también soy un dios a mi manera/ Un creador que no produce nada: /Yo me dedico a bostezar a full/ Y la fucsia parece bailarina". Esa nada es la acumulación de minucias, de productos del aburrimiento resueltos en la sosa repetitividad del absurdo verso final de todas las estrofas.

Hay otro punto importante: el mismo título "Versos sueltos" implica que estas obviedades podrían coincidir con las expectativas de lo que se espera de un poema, pero claramente esa coincidencia no tiene que ver con las hermosas imágenes o profundos sentimientos que un verso podría portar. Desde el punto de vista formal, aparte del estribillo del verso final, las estrofas son irregulares y no se observa un esquema fijo de rimas, pero sí hay una regularidad métrica destacable: todos son endecasílabos. Esto sí llama la atención, porque se nos está diciendo que lo que de verdad constituye a un 
verso como tal no es su inspiración lírica, sino simplemente un índice cuantitativo. Y bajo esa óptica, se puede entender que estos versos sueltos son, en realidad, versos producidos por azar, es decir, frases registradas o imaginadas por el autor que, al detectar que calzaban con una cierta medida métrica, los fue aceptando como tales y recogiendo, quizás en orden de llegada. El rol del antipoeta, entonces, se va acercando al de un recopilador callejero que tuviera todo el tiempo la grabadora encendida para capturar los endecasílabos inesperados. Así lo celebrará Armando Uribe en 1967: "uno de los descubrimientos implícitos en sus antipoemas: el endecasílabo de la vida corriente, de las noticias periodísticas o de la publicidad cotidiana, de la conversación trivial" (Parra, 2006: 943). Este procedimiento, evidentemente, acentúa los rasgos mediante los cuales la antipoesía intenta oponerse a la lírica tradicional: no sólo se busca ampliar el rango de temas y la perspectiva de un sujeto normal, sino que además la propia labor de escritura se desacraliza. No se trata de volcar adecuadamente la inspiración en un molde formal, con enlaces y contrastes bien elaborados, sino de algo bastante más sencillo: de recoger cualquier cosa que "suene como" un verso. Y es en este desafío, a nivel de las condiciones de la escritura y de la recepción, que esta poesía sí comienza a volverse una molestia.

En La camisa de fuerza (sección de poemas escritos entre 1962 y 1968, e incluida en su primera recopilación, Obra gruesa, de 1969) encontraremos otros dos poemas que profundizan esta línea. Uno de ellos es "Ideas sueltas":

No me gusta mirarme

En los espejos salpicados de sangre.

Preferible dormir al aire libre

Antes que compartir

El lecho de bodas con una tortuga.

El automóvil es una silla de ruedas.

Y el infeliz que mira a la madre

En el momento mismo del parto

Queda marcado para secula seculorum

(2006: 193).

Y el otro es "Frases":

No nos echemos tierra a los ojos 
El automóvil es una silla de ruedas

El león está hecho de corderos

Los poetas no tienen biografía

La muerte es un hábito colectivo

Los niños nacen para ser felices

La realidad tiende a desparecer

Fornicar es un acto diabólico

(2006: 182).

Son varios los puntos de interés que ofrece la comparación de ambos con "Versos sueltos". Aunque los dos son más breves, comparten la estructura acumulativa, el título de uno de ellos también lleva el adjetivo "sueltas", y las oraciones que las componen también son banalidades o clichés. En cuanto a su versificación, en el primero es bastante irregular, mientras que en el segundo predominan los endecasílabos, como en "Versos sueltos". En "Ideas sueltas" aún se percibe un sujeto en primera persona (como el que también emergía momentáneamente en "Versos sueltos"), por lo que ese desorden quizás sería el de su propio flujo de conciencia. En "Frases", en cambio, por fin desaparece esa voz para dar paso a una simple recolección cuyo organizador no está a la vista. Su mismo título, además, remarca una condición menor: aquí ni siquiera tenemos ni versos ni ideas (es decir, ni poesía ni pensamiento) sino solamente frases, sin ningún valor añadido.

Cada una de estas frases, a su vez, está contenida en un solo verso (como ocurre casi siempre en "Versos sueltos", pero no en "Ideas sueltas"), con lo que se resalta aún más el carácter inorgánico de la composición, que no necesita el calificativo de "sueltas" para advertir su dislocación. En consonancia con lo que ya advertía Uribe, el propio Parra le comentaba a José Donoso en una entrevista: "una de las características de mi poesía es que su unidad esencial no es la palabra, ni la estrofa, ni la frase, que sufre las inflexiones del ritmo. Mi unidad es el verso, que en mi poesía aparece como aislado, como una serie de pedradas lanzadas hacia el lector" (2006: liii). Es interesante tomar en cuenta esta consideración para calibrar los distintos tipos de efectos que pueden producirse en las diversas maneras en que se acomoda la poesía de Parra. En los collages del Quebrantahuesos (realizados junto a Enrique Lihn y Alejandro Jodorowsky en 1952), por ejemplo, se producía un choque al mezclar elementos incoherentes y de distinto origen dentro de una sola frase. En "Frases", en cambio, cada frase/verso es unitaria, y, como señala Binns en sus notas a las Obras completas, se observa "el estilo epigramático que será característico de los Artefactos" (2006: 962). En esa 
colección de poemas visuales, sin embargo, las "pedradas" se van lanzando una a la vez, a medida que se saca cada postal de la caja, mientras que en "Frases" se lanzan todas juntas. La fricción se produce a partir de sentencias que ni siquiera son divertidas ni tienen la carga visual del Quebrantahuesos ni los Artefactos. Esas obviedades se vuelven nebulosas en su conjunto, y se vacían de su carga significativa, por lo que, a mi juicio, el resultado es aún más violento: el lector, en vez de sonreír ante el ingenio del antipoeta, se queda esperando un chiste, una chispa que no salta. Resalta así el carácter "retorcido" que Cristián Huneeus detectaba en la antipoesía construida a partir de elementos pre-existentes: "No es uno el ready-made que se traslada, ya que el texto es un montaje de muchos ready-mades, y el shock provocado en los hábitos de recepción del lector se expande y contrae a medida que por un proceso asociativo éste va cobrando conciencia de los quiebres múltiples de su sistema de respuestas a la experiencia y de cómo está quebrada la experiencia misma" (2001: 30). De ese modo, lo que ocurre en este caso es que la acumulación indiscriminada de estos clichés los vuelve raros y ajenos: el lugar común deja de ser un lugar común.

Es más, estos materiales están tan devaluados que incluso pueden ser reiterados indistintamente. Como indica Binns (Parra, 2006: 962), "El automóvil es una silla de ruedas" es copiado tanto en "Frases" como en "Ideas sueltas", e incluso será incluido por tercera vez bajo el subtítulo "Aforismos chilenos" en "Cartas del poeta que duerme en una silla" (en Otros poemas, otra sección de Obra gruesa) (2006: 236). Si la labor del antipoeta se limita a la recolección de lugares comunes, no sorprenderá que más de alguno se repita. María Ángeles Pérez López destaca también que otras de estas "Frases" son reutilizadas: en la misma "Cartas del poeta..." se altera "Fornicar es un acto diabólico" por "Fornicar es un acto literario" (Parra, 2006: 235), y "La muerte es un hábito colectivo" aparecerá algunos años después ilustrada con algunos cadáveres corriendo en bibicleta, dentro de los Artefactos (2006: 373). Este procedimiento de "reciclaje literario" (2003: 170), como lo denomina Pérez López, refuerza el carácter insignificante de estos elementos, mero material de relleno.

La descripción de este tipo de obras como un tarro de basura, entonces, no resulta tan desacertada. A pesar de su simpleza, considero que "Versos sueltos", "Ideas sueltas" y particularmente "Frases" nos ayudan a comprender muy bien los efectos exasperantes de la antipoesía. La potencia de sus operaciones no se basa en la provocación, la parodia o el humor socarrón al que están acostumbrados los fans de Parra, sino más bien en lo contrario. Su oferta es plana y escueta: esto es lo que hay, nada más. 
Los lectores que citaba Hernán del Solar criticaban que alguien pensara que "esto" podía ser poesía. Pero no sólo Parra lo ha propuesto, sino que hay algunos que ya lo habían hecho antes y muchos que lo harán después. Un buen ejemplo de la tradición europea bastará para demostrar que existen antecedentes relevantes para estas "malas prácticas": el francés François Villon, nacido en 1431 y visto por última vez en 1463. El propio Parra comenta en 1969: "Un estudiante alemán, Thomas Stromm, vino el año pasado a Chile para escribir una tesis sobre la antipoesía y el resultado de su tesis se llama François Villon y Nicanor Parra; sostiene que hay una relación bastante grande entre los dos tipos de poesía, lo que no puede ser novedoso para nadie, ya que François Villon fue un poeta popular de su época, y yo he estudiado mucho esa línea. Los temas de la poesía popular se repiten en los diferentes idiomas especialmente en los de origen latino" (1969: 14). La poesía de Villon, al igual que la de otros antecedentes reconocidos por Parra, como Bocaccio y Chaucer, se hace cargo del lenguaje popular, pero lo que resulta relevante para una comparación con nuestro autor son las enumeraciones caóticas que estructuran algunas de sus piezas, como la "Ballade des menus propos" ("Balada de las menudencias"), la "Ballade des contre-verités" ("Balada de las contraverdades") y la "Ballade des proverbes" ("Balada de los proverbios"). En ellas, cada estrofa de 8 versos finaliza con un verso que se repite en las siguientes, del mismo modo que el estribillo "Y la fucsia parece bailarina" en "Versos sueltos". El contenido, como señalan sus títulos, es igualmente irrelevante, y su disposición desordenada contribuye a volverlos aún más insignificantes. Esto resulta particularmente patente en la "Balada de los proverbios", cuyo efecto resulta muy cercano al de "Frases", remarcando su cualidad de clichés. Ésta es su primera estrofa:

Tant gratte chêvre que mal gît,

Tant va le pot à l'eau qu'il se brise,

Tant chauffe on le fer qu'il rougit,

Tant le maille on qu'il se débrise,

Tant vaut l'homme comme on le prise,

Tant s'élogne il qu'il n'en souvient,

Tant mauvais est qu'on le déprise,

Tant crie l'on Nöel qu'il vient.

[...]

Tanto escarba la cabra que mal yace,

Tanto va el cántaro al agua que se rompe, 
Tanto se calienta el hierro que enrojece,

Tanto se le machaca que se quiebra,

Tanto vale el hombre como se le estima,

Tanto se marcha lejos que se le olvida,

Tanto se vuelve malo que se le odia,

Tanto se invoca Navidad que llega.

[...]

(Villon, 2005: 242-43).

Si, por otra parte, miramos el panorama posterior a la publicación de Versos de salón, comprobaremos que muchos otros autores han considerado igualmente que es posible escribir poesía a partir de materiales "no poéticos". Es evidente que este impulso ya venía desde las artes visuales en la vanguardia, con los readymades u objetos encontrados de Duchamp, pero es precisamente en la década de los '60 que sus usos literarios se acentúan en diversos contextos culturales. Un ejemplo particularmente llamativo son los Found Poems del norteamericano Bern Porter (quien, a tono con el cura Salvatierra, tituló otra de sus colecciones The Wastemaker). Sus poemas encontrados suelen ser fotocopias de listas, anuncios, diagramas, tablas, definiciones de diccionarios, etc., generalmente sin alteraciones y en un orden indefinido; es el rótulo de "poesía" lo que invita al lector a proyectar en ellos un potencial estético. Un caso posterior e insuficientemente considerado dentro de la tradición chilena son los Poemas encontrados de Jorge Torres, donde igualmente se fotocopian recortes de diarios (a veces tachados o subrayados), se transcriben cables noticiosos, y se citan fragmentos de textos literarios. En algunos se suma un título, para dirigir la lectura, y en general prima un carácter político, marcado por los años de producción del libro (la década de los '80). También podemos mencionar los Poemas plagiados del argentino Esteban Peicovich, donde se combinan anuncios de restaurantes, descripciones botánicas o frases escuchadas. Aquí, sin embargo, todos los textos han sido transcritos con la indicación de su origen y un título puesto por el autor para acentuar su ingenio o lirismo, como en el siguiente: "LA ETERNIDAD/ ¿Qué tiempo tiene?/ (Pregunta argentina referida a la edad de los niños)" (49). Un ejemplo contrario a esas pretensiones es el de Kenneth Goldsmith, uno de los precursores de la poesía conceptual estadounidense, cuya escritura basada en la recopilación apunta a reforzar el carácter insulso y absurdo de los materiales escogidos. Uno de sus libros, Head Citations, consiste simplemente en un listado de 800 "misheard lyrics", es decir, letras de canciones mal cantadas, que el autor escuchó o recogió de páginas 
web especializadas en este particular fenómeno. Éstas son algunas variaciones del coro de "Give peace a chance" de John Lennon: "10. All we are saying is kids need a dad./ 10.1 All we are saying, give hippies a chance./ 10.2 All we are saying is good piece of cheese./ $10.3 \mathrm{Oh}$, we are sailing, yes, give Jesus pants" (7). A diferencia de Porter (2011), Torres (1991) o Peicovich (2000), Goldsmith (2002) ni siquiera se molesta en presentar este conjunto como una serie de poemas, y es por eso que su efecto se acerca más, a mi juicio, al interés de Parra por reunir sus "Frases" sin pretender otorgarles otra carga que la de su propia condición anodina.

Dentro del OuLiPo francés también se ha trabajado manipulando los clichés o "langage cuit" (lenguaje cocido), según la expresión de Robert Desnos, quien tomaba esas frases para cambiar sus adjetivos por sus antónimos. Los oulipianos proponen extender este procedimiento con proverbios, citas literarias clásicas, lemas políticos, títulos de libros, etc. Incluso realizan "liftings" a algunos proverbios, modernizando sus elementos, o crean las "locutions introuvables", donde pegan las mitades de expresiones distintas: "avec 'tirer le diable par la queue' et 'bâtir des châteaux en Espagne', on obtient deux 'locutions introuvables': 'tirer le Diable en Espagne' et 'bâtir des châteaux par la queue" (Bénabou y Fournel, 2009: 592). Aunque en estos casos los clichés transcritos son manipulados, también consiguen llamar la atención sobre su carácter absurdo, al igual que en las acumulaciones de Villon y Parra. Por otra parte, en el OuLiPo también se practicó el procedimiento del poema encontrado ("poème fondu"), pero de una manera distinta a las anteriores. Aquí no se trata de recoger un texto no literario o una imagen, sino que se toma un poema ya existente y, sin alterar sus elementos, se extrae un poema más breve; de un soneto, por ejemplo, es posible obtener un haiku.

Aunque ya hemos visto que el principal suministro de Nicanor Parra era "el lenguaje de todos los días" (2006: 143), también hay ocasiones en que se ha basado en obras literarias. Uno de sus textos más interesantes es "Yo me sé tres poemas de memoria", publicado en Hojas de Parra (2011: 249-51), en el que simplemente copia los textos de tres poemas clásicos de la literatura chilena. Rafael Rubio señala algunas alteraciones en la transcripción de los textos originales, de los que además se omiten los títulos y autores ("Canción", de Juan Guzmán Cruchaga, "Nada" de Carlos Pezoa Véliz y "Elegía del indio triste que regresa" de Víctor Domingo Silva), y propone que esas operaciones funcionan como una burla a la censura de la dictadura, recontextualizando políticamente los poemas que ha "plagiado" (2010: 22). Pero hay otro caso que resonará de manera más definida con 
los ejemplos que he venido citando, y que fue incluido en "News from Nowhere", un grupo de textos publicados en la célebre revista Manuscritos en 1975, con una nota que indica que se trata de "los manuscritos abandonados o rechazados por Parra; los que ha considerado como restos, excesos, desaciertos, actos gratuitos, licencias, pre-textos o también material de reserva", y que expone los libros de Parra "a la revisión de sus propios desechos" (1975: 90-91). Se trata de "Found Poem", que consiste únicamente en la fotocopia e impresión en negativo (fondo negro y letras blancas ${ }^{2}$ ) de un soneto de Shakespeare, con una nota que indica que fue descubierto en The Oxford Book of English Verse (1975: 108). No tengo la certeza de que Parra haya conocido por entonces los Found Poems de Porter (que habían sido editados en 1972 en New York por Something Else Press, la editorial de Dick Higgins, miembro de Fluxus), pero lo que importa es que el procedimiento de Parra es justamente el contrario. No se trata de "elevar" un anuncio o un recorte de diario al estatus de poesía, sino de "rebajar" un clásico de la historia literaria al mismo nivel de un juego vanguardista. Dicho de otro modo, más que ponerle un marco literario a un objeto no literario, esto consiste en reemplazar un marco de lujo, con toda la pátina de la tradición, por un marco de menor calidad, lo que se acentúa por su impresión en negativo. Paralelamente, el rol del "encontrador" también es disminuido: ya no es el de una persona perceptiva, capaz de descubrir la carga poética de cualquier elemento de la vida cotidiana (como lo hacían Porter, Torres o Peicovich) o al menos de tener la agudeza para extraer un poema breve desde un poema mayor (como lo hacían los oulipianos), sino de alguien cuya tarea apenas se ha limitado a verificar que un poema de un autor conocidísimo incluido en una antología de difusión masiva puede ser un poema. Este procedimiento (que, como apunta Raúl Zurita, puede considerarse un antecedente de su traducción del King Lear (Parra, 2011: 1075)), nos permite imaginar a Parra como una especie de Rey Midas inverso, capaz de absorber e inutilizar las energías líricas de todo lo que toca. No sólo nos ha demostrado que una banalidad puede convertirse en gran literatura, sino también que la gran literatura puede convertirse en una banalidad.

\footnotetext{
${ }^{2}$ En la edición de las Obras completas aparece en fondo blanco y letras negras (2011: 921).
} 


\section{REFERENCIAS}

Bénabou, Marcel y Paul Fournel. (2009). Anthologie de l'OuLiPo. París: Gallimard.

Goldsmith, Kenneth. (2002). Head Citations. Great Barrington: The Figures.

Huneeus, Cristián. (2001). Artículos de prensa (1969-1985). Eds. Daniela Huneeus y Manuel Vicuña. Santiago: DIBAM.

OuLiPo. OuLiPo. Sitio web: http://www.oulipo.net/.

Parra, Nicanor. (1969). "Nicanor Parra, o el artefacto con laureles". Entr. Mario Benedetti. Marcha, 17 de octubre, 14-15. . (1975). "News from Nowhere". Manuscritos, 1, 89-116. (2006). Obras completas I. 1935-1972. Eds. Niall Binns e Ignacio Echevarría. Barcelona: Galaxia Gutenberg / Círculo de Lectores. (2011). Obras completas II. 1975-2006. Eds. Niall Binns e Ignacio Echevarría. Barcelona: Galaxia Gutenberg / Círculo de Lectores.

Peicovich, Esteban. (2000). Poemas plagiados. Alzira: Germania.

Pérez López, Ma. Ángeles. (2003). La autotextualidad en Nicanor Parra: Acotar/agotar/reciclar. Anales de Literatura Chilena, 4, 165-75.

Porter, Bern. (2011). Found Poems. Ed. Mark Melnicove. New York: Nightboat Books.

Rubio, Rafael. (2010). Plagio y censura en un texto de Nicanor Parra. Grifo, 19, 19-22.

Solar, Hernán del. (1962). Nicanor Parra: Versos de salón. La Nación, 19 de octubre, 4.

Torres, Jorge. (1991). Poemas encontrados y otros pre-textos. Valdivia: Ediciones Paginadura.

Villon, François. (2005). Poesía completa. Ed. Gonzálo Suárez. Madrid: Visor Libros. 